\title{
EDITORIAL
}

\section{Intervention trials and ventilation distribution in mild cystic fibrosis lung disease: will it all come out in the wash?}

\author{
G.L. Hall*,\# and J. Stocks
}

$\mathbf{T}$ he identification of clinically relevant end-points for use in clinical trials of new treatments in cystic fibrosis (CF) lung disease is an ongoing problem for physicians and researchers working in the field of CF care. Lung disease almost certainly starts in early infancy [1-6] and is progressive, leading to significant structural lung disease in the preschool years [7]. Despite this, the majority of young children with CF tend to have spirometry within the normal range at early school age $[1,8,9]$. It is well recognised that relying on spirometry alone to identify children at risk of progressive lung disease has significant limitations. This has led to renewed emphasis on the assessment of physiological outcomes in infancy and the preschool years, as well as increased focus on lung function tests that are more sensitive to early lung dysfunction than spirometry [10-13].

One such outcome is the assessment of ventilation inhomogeneity obtained from the multiple breath inert gas washout test (MBW), the most commonly reported outcome being the lung clearance index (LCI). A significant advantage of this technique is that it can be applied from infancy through to adulthood, with only minor changes in equipment and methodology, particularly from the preschool years onwards [14-16]. The LCI has been shown to be abnormal in the presence of normal spirometry in both preschool children [7] and older children with CF [9, 17-22], suggesting that it is a more sensitive marker of early lung disease in such children. The LCI has also been found to be strongly associated with structural changes on computed tomography scans $[19,20,21]$.

Nevertheless, there is limited evidence regarding the use of LCI as an outcome measure following therapeutic interventions in children with CF. ROBINSON et al. [23] demonstrated a small but significant group improvement in LCI of -0.48 (which equated to a mean reduction of $3.8 \%$ ) following intravenous antibiotic treatment for a respiratory exacerbation in 28 schoolaged children with $\mathrm{CF}$, but noted marked heterogeneity of

\footnotetext{
*Telethon Institute for Child Health Research, Centre for Child Health Research, University of Western Australia, ${ }^{\#}$ Respiratory Medicine, Princess Margaret Hospital for Children, Perth, Australia "Portex Unit, Respiratory Medicine and Physiology, University College London, Institute of Child Health, London, UK.

CORRESPONDENCE: G.L. Hall, Paediatric Respiratory Physiology, Telethon Institute for Child Health Research, P0 Box 855, West Perth, WA 6872, Australia. E-mail: grahamh@ichr.uwa.edu.au
}

response between patients. FucHs et al. [24] performed baseline MBW in 27 schoolchildren with $\mathrm{CF}$, with measurements repeated $90 \mathrm{~min}$ later, after administrating chest physiotherapy to 16 of the patients, with no intervention in the remaining 11. Their results indicated that physiotherapy did not appear to have any significant effect either on mean LCI nor its within-test variability, although within-subject between-test changes in LCI over this period could be as high as 1.4. These preliminary studies suggest that the LCI may be a useful outcome measure in intervention trials in school-aged children with mild CF lung disease.

Until recently, no studies have examined changes in LCI in a randomised placebo crossover trial. AmIN et al. [17] demonstrated the potential use of LCI in such studies when they reported a statistically significant improvement in LCI, but not spirometry, in response to hypertonic saline in 19 children with mild CF lung disease. In the present issue of the European Respiratory Journal, the same authors report a significant improvement in LCI in a placebo-controlled randomised crossover trial of dornase alfa in school-aged children with mild CF lung disease [25]. In the study, children with normal spirometry underwent a 12-week crossover trial with 4 weeks' treatment of dornase alfa or placebo separated by a 4-week washout period. Following dornase alfa treatment, LCI improved significantly when compared to placebo (mean \pm SD $0.9 \pm 1.44$ ). Despite the small sample size, with potential for type 1 errors, this provides further important evidence to support the use of LCI as an objective outcome in such trials. The authors are to be congratulated on using an appropriate study design to take into account the normal variability that may occur over time in the absence of any active intervention, a factor that is often ignored in such studies, irrespective of outcome used. However, caution needs to be exercised when interpreting the clinical significance of such changes within individual patients [26].

As previously reported by ROBINSON et al. [23], despite the significant group improvement in LCI in response to therapeutic intervention, marked heterogeneity in individual responses may occur, not least because improvement in overall lung function may result in subsequent ventilation of previously unventilated portions of the lung, potentially resulting in an increase rather than decrease in ventilation inhomogeneity. A further problem when interpreting results from intervention studies is that authors frequently report the proportion 
of subjects showing an "improvement" based purely on the direction of change, without considering the magnitude of such change in relation to natural variability over time, which is frequently higher in disease than in health.

Based on the relative changes in LCI during the pooled placebo periods of both of their recent studies, AmIN et al. [17, 25] have suggested that a clinically relevant change in LCI over an 8week period equates to $\sim 15 \%$. Using this cut-off, they concluded that four out of 17 children demonstrated a clinically significant improvement (i.e. decrease) in LCI. Alternatively, had results been interpreted in relation to the absolute rather than the relative variability, as has been proposed by some authors [9, 27-29], the coefficient of repeatability for LCI (derived from the mean \pm SD of the pooled placebo periods of $0.07 \pm 1.16[17,25])$ would be 2.32 . Using this threshold, three $(18 \%)$ children would have demonstrated a clinically significant change in LCI following dornase alfa treatment.

As outlined above, very few studies have reported the between-test repeatability of LCI. FUCHS et al. [24] demonstrated repeated LCI in 11 children with CF, who were 516 yrs of age, and in whom a change of $0.07 \pm 0.42$ occurred over a 90 -min period (short-term threshold of repeatability of 0.91). The same group reported changes in LCI in healthy children over periods of $1 \mathrm{~h}(\mathrm{n}=24)$ and 9 months $(n=34)$ of $0.13 \pm 0.49$ and $0.17 \pm 0.52$, respectively [30]. These results equate to a similar range of normal variability as recently reported by AURORA et al. [9] in 45 healthy young children in whom the mean $(95 \% \mathrm{CI})$ within-subject change in LCI was $0.0(-0.2-0.2)$, with a $95 \%$ range of $-1.3-1.3$, when measurements were repeated after an interval of $\sim 4$ yrs. Children with CF assessed during the same study were only considered to have demonstrated significant decline or improvement in lung function if their change in LCI over time was outside the $95 \%$ range (defined by the 2.5 th to 97.5 th percentiles from the controls). Results from the study by AURORA et al. [9] also suggest that gas washout studies have the potential for identifying young children with CF who may benefit from more aggressive therapy, as well as providing an objective outcome measure for early intervention studies in infants and preschool children with CF.

In conclusion, the LCI remains one of the most promising outcome measures with which to distinguish children with relatively mild, early CF lung disease from those who have undetectable or no lung disease [9]. The study by AMIN et al. [25] provides important preliminary evidence that LCI has a role as an outcome measure in clinical trials in preschool and school-age children with mild CF lung disease. These results now need to be confirmed in a much larger trial. Future research needs to clarify the between-test repeatability of LCI in both healthy children and those with CF to ensure that the intrinsic variability as well as disease-related variability of LCI is clearly understood. Placebo-controlled intervention trials conducted in larger numbers of children with CF over longer periods of time will provide critical evidence of the role of the LCI both as an outcome measure in clinical trials and in the day-to-day management of children with CF.

\section{STATEMENT OF INTEREST}

None declared.

\section{REFERENCES}

1 Kozlowska WJ, Bush A, Wade A, et al. Lung function from infancy to the preschool years after clinical diagnosis of cystic fibrosis. Am J Respir Crit Care Med 2008; 178: 42-49.

2 Linnane BM, Hall GL, Nolan G, et al. Lung function in infants with cystic fibrosis diagnosed by newborn screening. Am J Respir Crit Care Med 2008; 178: 1238-1244.

3 Lum S, Gustafsson P, Ljungberg H, et al. Early detection of cystic fibrosis lung disease: multiple-breath washout versus raised volume tests. Thorax 2007; 62: 341-347.

4 Ranganathan SC, Stocks J, Dezateux C, et al. The evolution of airway function in early childhood following clinical diagnosis of cystic fibrosis. Am J Respir Crit Care Med 2004; 169: 928-933.

5 Brennan S, Hall GL, Horak F, et al. Correlation of forced oscillation technique in preschool children with cystic fibrosis with pulmonary inflammation. Thorax 2005; 60: 159-163.

6 Sly PD, Brennan S, Gangell C, et al. Lung disease at diagnosis in infants with cystic fibrosis detected by newborn screening. Am J Respir Crit Care Med 2009; 180: 146-152.

7 Stick SM, Brennan S, Murray C, et al. Bronchiectasis in infants and preschool children diagnosed with cystic fibrosis after newborn screening. J Pediatr 2009; 155: 623-628.

8 Aurora P, Bush A, Gustafsson P, et al. Multiple-breath washout as a marker of lung disease in preschool children with cystic fibrosis. Am J Respir Crit Care Med 2005; 171: 249-256.

9 Aurora P, Stanojevic S, Wade A, et al. Lung clearance index at 4 years predicts subsequent lung function in children with cystic fibrosis. Am J Respir Crit Care Med 2010; [Epub ahead of print DOI: 10.1164/rccm.200911-1646OC].

10 Ranganathan S, Linnane B, Nolan G, et al. Early detection of lung disease in children with cystic fibrosis using lung function. Paediatr Respir Rev 2008; 9: 160-167.

11 Gangell CL, Horak F Jr, Patterson HJ, et al. Respiratory impedance in children with cystic fibrosis using forced oscillations in clinic. Eur Respir J 2007; 30: 892-897.

12 Davis SD, Brody AS, Emond MJ, et al. Endpoints for clinical trials in young children with cystic fibrosis. Proc Am Thorac Soc 2007; 4: 418-430.

13 Tiddens HA, Donaldson SH, Rosenfeld M, et al. Cystic fibrosis lung disease starts in the small airways: can we treat it more effectively? Pediatr Pulmonol 2010; 45: 107-117.

14 Aurora P, Kozlowska W, Stocks J. Gas mixing efficiency from birth to adulthood measured by multiple-breath washout. Respir Physiol Neurobiol 2005; 148: 125-139.

15 Gustafsson PM. Inert gas washout in preschool children. Paediatr Respir Rev 2005; 6: 239-245.

16 Robinson PD, Goldman MD, Gustafsson PM. Inert gas washout: theoretical background and clinical utility in respiratory disease. Respiration 2009; 78: 339-355.

17 Amin R, Subbarao P, Jabar A, et al. Hypertonic saline improves the LCI in paediatric patients with CF with normal lung function. Thorax 2010; 65: 379-383.

18 Aurora P, Gustafsson P, Bush A, et al. Multiple breath inert gas washout as a measure of ventilation distribution in children with cystic fibrosis. Thorax 2004; 59: 1068-1073.

19 Ellemunter H, Fuchs SI, Unsinn KM, et al. Sensitivity of lung clearance index and chest computed tomography in early CF lung disease. Respir Med 2010; 104: 1834-1842.

20 Owens CM, Aurora P, Stanojevic S, et al. Lung clearance index and HRCT are complementary markers of lung abnormalities in young children with CF. Thorax 2010: (In press).

21 Gustafsson PM, De Jong PA, Tiddens HA, et al. Multiple-breath inert gas washout and spirometry versus structural lung disease in cystic fibrosis. Thorax 2008; 63: 129-134.

22 Kraemer R, Blum A, Schibler A, et al. Ventilation inhomogeneities in relation to standard lung function in patients with cystic fibrosis. Am J Respir Crit Care Med 2005; 171: 371-378. 
23 Robinson PD, Cooper P, Van Asperen P, et al. Using index of ventilation to assess response to treatment for acute pulmonary exacerbation in children with cystic fibrosis. Pediatr Pulmonol 2009; 44: 733-742.

24 Fuchs SI, Toussaint S, Edlhaimb B, et al. Short-term effect of physiotherapy on variability of the lung clearance index in children with cystic fibrosis. Pediatr Pulmonol 2010; 45: 301-306.

25 Amin R, Subbarao P, Lou W, et al. The effect of dornase alfa on ventilation inhomogeneity in patients with cystic fibrosis. Eur Respir J 2011; 37: 806-812.

26 Chinn S. Statistics in respiratory medicine. 2. Repeatability and method comparison. Thorax 1991; 46: 454-456.
27 Herpel LB, Kanner RE, Lee SM, et al. Variability of spirometry in chronic obstructive pulmonary disease: results from two clinical trials. Am J Respir Crit Care Med 2006; 173: 1106-1113.

28 Oostveen E, Dom S, Desager K, et al. Lung function and bronchodilator response in 4-year-old children with different wheezing phenotypes. Eur Respir J 2010; 35: 865-872.

29 Thamrin C, Gangell CL, Kusel MM, et al. Expression of bronchodilator response using forced oscillation technique measurements: absolute versus relative. Eur Respir J 2010; 36: 212.

30 Fuchs SI, Eder J, Ellemunter H, et al. Lung clearance index: normal values, repeatability, and reproducibility in healthy children and adolescents. Pediatr Pulmonol 2009; 44: 1180-1185. 